\title{
Case Management in Primary Care for Frequent Users of Health Care Services With Chronic Diseases: A Qualitative Study of Patient and Family Experience
}

\author{
Catherine Hudon, MD, PbD, CFPC $C^{1,2}$ \\ Maud-Christine Chouinard, RN, \\ $\mathrm{PbD}^{3,4}$
}

Fatoumata Diadiou, SW, MA(c) ${ }^{3}$

Mireille Lambert, $M A^{3}$

Danielle Bouliane, SW, MA(c) ${ }^{3}$

'Département de médecine de famille et médecine d'urgence, Université de Sherbrooke, Québec, Canada

${ }^{2}$ Centre de recherche du Centre hospitalier universitaire de Sherbrooke, Québec, Canada

${ }^{3}$ Centre de santé et de services sociaux de Chicoutimi, Québec, Canada

${ }^{4}$ Département des sciences de la santé, Université du Québec à Chicoutimi, Québec, Canada

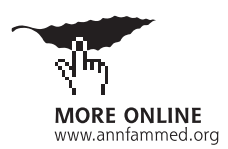

Conflicts of interest: authors report none.

\section{CORRESPONDING AUTHOR}

Catherine Hudon, MD, PhD, CFPC 3001, 12e Avenue Nord

Sherbrooke, Québec, Canada, J1H 5N4 catherine.hudon@usherbrooke.ca

\begin{abstract}
PURPOSE Although case management (CM) is increasingly being implemented to address the complex needs of vulnerable clienteles, few studies have examined the patient experience of $\mathrm{CM}$. This study aimed to examine the experience of patients and their family members with care integration as part of a primary care $\mathrm{CM}$ intervention. Patients in the study were frequent users of health care services who had chronic diseases.
\end{abstract}

METHODS A descriptive, qualitative approach was conducted involving 25 patients and 8 of their family members. Data were collected through in-depth interviews of the patients and 2 focus groups of family members and were analyzed thematically.

RESULTS While some participants did not fully understand the CM intervention and a few believed that it involved too many appointments, the CM nurses were patients' preferred contact with primary care. The nurses actively involved the patients in developing and carrying out their individualized services plans (ISPs) with other health care partners. Patients felt that their needs were taken into consideration, especially regarding access to the health care system. The case manager facilitated access to information as well as communication and coordination among health care and community partners. This improved communication comforted the patients and nurtured a relationship of trust. Participants were actively involved in decision-making. Their ISPs helped them know where they were going and improved transitions between services.

CONCLUSIONS The experience of patients and family members was overall very positive regarding care integration. They reported improved access, communication, coordination, and involvement in decision-making as well as better health care transitions.

Ann Fam Med 2015;13:523-528. doi: 10.1370/afm.1867.

\section{INTRODUCTION}

Tn Canada as in many other industrialized countries, ${ }^{1,2}$ close to $80 \%$ of the costs of health care are attributable to $10 \%$ of the population. ${ }^{3}$

Many of these people use hospital services frequently for increasingly complex health needs. ${ }^{4,5}$ These frequent users, who require care and services from many partners in the health care and social services system and the community network, are more at risk of encountering difficulties in the integration of care and more at risk for incapacity and mortality.

Faced with this issue, case management $(\mathrm{CM})$ is more and more recognized internationally as an appropriate intervention to improve patient satisfaction and quality of life $^{6}$ and reduce costs associated with frequent users of services..$^{1,4,6,7}$ Case management responds to the complex needs of a very vulnerable clientele through a structured approach that promotes self-management support and better integration of health care services. ${ }^{8}$ Many CM programs have been implemented and evaluated around the world, particularly in the United Kingdom ${ }^{9-11}$ and the United States. ${ }^{12-14}$ 
As proposed by the National Collaboration for Integrated Care and Support, ${ }^{15}$ "integrated care... is about individuals and communities having a better experience of care and support, experiencing less inequality and achieving better outcomes." That is why we have embraced the concept of the individual lying at the heart of integrated care and support and being the organizing principle for services, as expounded by the NHS Future Forum. ${ }^{15}$ Despite increasing interest in $\mathrm{CM}$ in primary care for frequent users of health care services, ${ }^{8,16,17}$ very few studies have examined patients' and family members' experiences, and none of these studies have focused specifically on care integration.

The 3 studies closest to ours in intent examined patients' and family members' experience of CM provided by community matrons in the United Kingdom. Results of these studies documented a positive impact on patient care mainly in 6 areas: access, ${ }_{1}^{15,18,19}$ patient advocacy, ${ }_{1}^{15,19}$ psychosocial support, ${ }^{15,19}$ improved communication, ${ }^{18}$ coordination of services, ${ }^{18,19}$ and comprehensive patient education and self-management support. ${ }^{19}$

Although these 3 studies were the first to provide relevant information about frequent users' experience of $\mathrm{CM}$, other studies are needed in different contexts where professionals other than community matrons play a CM role. ${ }^{19}$ Our study aimed to examine the experience of patients and their family members with care integration in Canada as part of a primary care $\mathrm{CM}$ intervention involving registered nurses as care managers rather than community matrons. Patients in the study were frequent users of health care services who had chronic diseases.

\section{METHODS}

\section{Design}

We conducted a descriptive, qualitative approach as defined by Sandelowski. ${ }^{20}$ This approach allowed us to provide a comprehensive description of participants' experience in plain language while remaining close to the data, minimizing researchers' influence on interpretation while reflecting patient perspectives. ${ }^{20}$

\section{V1SAGES Project, Case Management Intervention and Context}

This qualitative study took place in the context of the implementation analysis of the V1SAGES project described in a previous article, ${ }^{21}$ which aimed to implement and evaluate a 6-month CM intervention by nurses in 4 family medicine groups, including 38 practices, in the Saguenay-Lac-Saint-Jean region of the Province of Quebec (Canada). A family medicine group is an administrative arrangement for existing practices in which primary care physicians are grouped together to collaborate with nurses to offer primary care services to a group of registered patients. It offers access to care 10 hours a day, 7 days a week, through regular appointments, walk-in clinics, home visits, and after-hours health coverage using direct telephone lines and emergency on-call services. ${ }^{22}$

The CM intervention was seen as a collaborative, dynamic, and systematic approach to ensure and coordinate care and services for a defined clientele based on interdisciplinary practice. The registered nurses evaluated, planned, implemented, coordinated and prioritized options and services according to patient health needs, in close collaboration with the involved partners. The intervention focused on 4 main components ${ }^{8}$ :

- Thorough evaluation of patient needs and resources

- Establishment and maintenance of a patientcentered individualized service plan

- Coordination of services among partners

- Self-management support for patients and families

Patients had to be aged between 18 and 80 years, have at least 1 chronic disease (diabetes, cardiovascular disease, respiratory disease, musculoskeletal disease, or chronic pain), and be identified by their family physician as a frequent user of health care services (based on statistics on their use of hospital services) who would benefit from participating in the intervention. Participants also had to be willing to share their opinions about the research topic. Ethics approval for this research was obtained from the ethics review board of the Centre de Santé et de Services Sociaux de Chicoutimi.

\section{Conceptual Model}

Patient experience of integration was examined according to the 6 dimensions of services integration suggested by the National Collaboration for Integrated Care and Support ${ }^{15}$

- Consideration of patient and family needs

- Communication with the patient and between health care providers

- Access to information

- Involvement in decision-making

- Care planning

- Transitions between various health professionals

\section{Participants}

A convenience sample of 25 patients (14 women and 11 men) who participated in the V1SAGES CM intervention were selected using a maximal variability sampling approach ${ }^{23}$ regarding their age, sex, family medicine group (clinic), and chronic disease, between November 2013 and October 2014 (Table 1). People with cognitive impairment, uncontrolled psychiatric illness, or serious hearing impairment were excluded from the 
study. Eight family members ( 7 women and 1 man, all spouses) also participated in 2 focus groups.

\section{Data Collection}

In-depth individual interviews were used to capture the richness and nuances of experiences, with a focus on participant perspectives. ${ }^{24-26}$ After providing written informed consent, each participant completed a short demographic questionnaire and participated in a 1-hour interview conducted by a social worker trained in qualitative research (D.B.). The interview guide (Supplemental appendix, available at http://www. annfammed.org/content/13/6/523/suppl/DC1) included open-ended questions asking patients to describe their experience with the $\mathrm{CM}$ intervention. The same interviewer facilitated the 2 focus groups of family members to elicit their experience about the CM intervention. All interviews and focus groups were audiotaped and transcribed verbatim.

\section{Analysis}

Two authors from different professional backgrounds (F.D., a social worker, and M.L., an anthropologist) read the transcripts and analyzed them independently using mixed coding as described by Miles and Huberman. ${ }^{27}$ They first conducted an inductive thematic analysis of the data and subsequently used the 6 main themes of the conceptual integration mode $1^{15}$ as a framework to present relevant results. Discrepancies and disagreements were discussed with other co-researchers. Pair debriefing, triangulation of researcher backgrounds (C.H., a family physician, M-C.C., a registered nurse ${ }_{i}$ F.D., D.B., and M.L.) and

\begin{tabular}{|c|c|c|}
\hline Characteristic & Number & Percentage (\%) \\
\hline \multicolumn{3}{|l|}{ Sex } \\
\hline Male & 11 & 44 \\
\hline Female & 14 & 56 \\
\hline \multicolumn{3}{|l|}{ Family revenue (CaD\$) } \\
\hline 10,000 to 19,999 & 5 & 20 \\
\hline 20,000 to 29,999 & 3 & 12 \\
\hline 30,000 to 39,999 & 4 & 16 \\
\hline 40,000 to 49,999 & 6 & 24 \\
\hline$\geq 50,000$ & 6 & 24 \\
\hline \multicolumn{3}{|l|}{ Marital status } \\
\hline Married / common law & 19 & 76 \\
\hline Separated / divorced & 3 & 12 \\
\hline Widowed & 2 & 8 \\
\hline Single & 1 & 4 \\
\hline Mean age (SD) & $\begin{array}{l}60.1 \text { SD } \\
(15.26)\end{array}$ & \\
\hline
\end{tabular}

team validation minimized the effect of researcher subjectivity, thus improving the credibility of the work. ${ }^{28}$ Transparency in analysis and reporting was achieved by providing extensive verbatim quotes. Interviews were conducted until the point of data saturation was reached. ${ }^{25,28}$ A sample size of 25 patients is considered adequate in descriptive qualitative studies. ${ }^{29}$ Considering that focus groups with family members were intended to triangulate interview results, we did not aim to achieve data saturation for the focus groups. NVivo 10 software (QSR International Pty Ltd) was used to manage the qualitative data.

\section{RESULTS}

Participants confirmed that the CM nurse was their preferred contact with primary care, as explained by a woman aged 72 years: "Since the V1SAGES program arrived... if I have a cold or whatever, I will call the nurse." (P [Participant identifier] 13) This access to the case manager was greatly appreciated and helped the participants feel well supported, as expressed by 1 spouse: "My partner and I, we really appreciated this; because we'd have a closer follow-up, we felt confident. And I worry a lot about my partner's health; therefore I felt reassured to know that there was a team there." (FG [Focus group identifier] 2) Some participants even talked about the advocacy role of the nurse: "The frustrations I had towards the doctor, sometimes I would not express them... but I would express them to the nurse and she would tell the doctor." (P25)

\section{Consideration of Patient and Family Needs}

Patients felt that their needs were taken into consideration. They were actively involved in developing their individualized services plans: "...we looked at the range of possibilities [of services]. Like the physiotherapist, that will be good for me. The psychologist, that will be good, for sure." (P10) Their needs were also considered regarding access to their primary care providers or specialists. As explained by a young woman who was very busy, "The people [the providers] tried to be organized. They would offer the possibility to group my appointments together so I wouldn't have to make too many trips." (P10)

A few participants had difficulty going to their primary care clinic because of fatigue or financial concerns: "Well that [transport] was $\$ 8$ here, $\$ 8$ there.... I found that was a lot of $\$ 8$. And last year I had a lot of expenses, unexpected, so I was a bit tight financially, so that counted for me, a lot." (P09)

Patients noticed that providers were also attentive to the needs of their family, as reported by this woman aged 70 years: "They offered respite services to my husband 
because he took care of me on his own....We used the Popote Express [a charitable canteen]...twice a week to give my husband a break with meal preparation." (P03)

\section{Communication With the Patient and Between Health Care Providers}

Easy access to the CM nurse facilitated communication. This also allowed a closer follow-up when needed, as this man aged 59 years explained: "After the first meeting with the nurse, she would often ask about me; she called me almost every fortnight to know how I was doing." (P08)

One family member noted, as did many other participants, that privileged access to the CM nurse fostered a better communication with their family physician: "First the patient speaks to the nurse and she provides the information to the doctor $;$ he is already in the know. So when I get there, well, he already has a good idea of what's going to happen." (FG01) The CM nurse and the individualized service plan facilitated a better coordination with and among health care and community partners. This improved communication comforted them and nurtured a relationship of trust:

"... a bond of trust because I was under the impression that I wouldn't be judged...She [the nurse] was always encouraging and would show me that I took good care of myself, that I knew what to do. So I found it very interesting, this way of addressing matters." (P05)

Even though overall communication was improved by the CM intervention, a few patients mentioned that it was difficult to reach some professionals: "The kinesiologist is hard to reach. She's not at her office often...." (P21)

\section{Access to Information}

Participants explained that the improved communication enabled by the CM intervention also allowed better access to personalized information: "The information is a bit closer. Like me: I was advised also on certain aspects concerning antidepressants, nutrition and diet." (P15) And, "From the first encounter, she told me everything just as I told you, that I had the right to a nutritionist, I had the right to a kinesiologist, the one for sports...." (P07) Some participants, however, did not clearly understand the CM intervention at the beginning of the project: "At the beginning I didn't really understand the magnitude, in fact, all the components that you told me.... What I didn't understand is where it fit." (P05)

\section{Involvement in Decision-Making}

Participants said that they were actively involved in decision-making and felt that their choices were respected. "...the encounters I had with different professionals, so as not to multiply the services and to know whom to go to, I found that good. They all got together for half an hour and as I was saying earlier, half an hour with me, they offered their services to me and I chose what I was willing to accept." (P03)

\section{Care Planning}

The development of individualized service plans brought together the patients and their families with concerned health care professionals and community organization members. These plans helped participants know where they were going, as expressed by a man aged 74 years: "...we can have the care plans...we know where to go...." (P19) A few patients, however, found there to be too many appointments: "...I don't like having too many appointments. Unless you start early, 'cause after that it's as if I lose a day." (P04)

\section{Transitions Between Health Professionals}

The CM nurse helped to coordinate services "because she was the link with the others." (P21) This coordination role, complementary to the individualized services plan, improved transitions between services as well as collaboration among health care partners. "Even the doctor, the cardiologist, the nurse, it was like a group. I found they worked well together." (FG01)

One participant explained, as did others, that she had gotten help in health care navigation: "I found this excessively constructive. Really because I didn't know... again in the sense that you have to make appointments, ... and they're all services that I knew existed but to be able to use them..." (P07)

In the context of a new intervention, some participants still had the reflex to go to the emergency department: "So we, yes for sure with the V1SAGES project, we feel supported, when something happens, I call the family medicine group and they advise us...but we still have the emergency department mentality." (FG01)

\section{DISCUSSION}

To our knowledge, this study was the first to examine the experience of people with chronic disease, frequent users of health care services, who participated in a $\mathrm{CM}$ intervention in primary care, and family members, regarding care integration. The experience of patients and family members was overall very positive. Participants confirmed that, as their preferred contact with primary care, their CM nurse could inform, educate, support, and help them navigate in the health care system as well as advocate for them. The CM nurses actively involved them in developing and carrying out their individualized services plan with other health care partners. Participants reported improved access, com- 
munication, coordination, and involvement in decisionmaking as well as better health care transitions.

As we mentioned above, to date, 3 studies conducted in England examined patient experience of CM provided by community matrons. ${ }^{16,18,19}$ Community matrons are highly experienced senior nurses who work closely with patients in the community to provide, plan, and organize their care. As well as providing nursing care, community matrons act as case managers. They are a single point of contact for care, support, and advice, typically for a caseload of approximately 50 very high-intensity users. ${ }^{30}$ The context of our study was different. The case managers were registered nurses with bachelor's degrees and 10 to 17 years of experience, who worked in primary care clinics and who received 3 days of training in $\mathrm{CM}$ and self-management support. They continued to develop their skills through action learning, working with other CM nurses involved in the project through monthly meetings in which they exchanged and learned from their experiences. ${ }^{31}$ The importance of action learning as a supportive and proactive strategy for the development of a CM role has already been described in the context of the implementation of $\mathrm{CM}$ with community matrons. ${ }^{32}$ Most CM nurses spent approximately one-half of their time in $\mathrm{CM}$, with a caseload of about 25 frequent users of health care services, and the remaining one-half in other primary care duties such as triage of clients without appointments and follow-up of chronic disease.

Although the English studies did not specifically evaluate care integration, they reported positive experiences with better access to health care services and with better communication and coordination, in accordance with our study. ${ }^{16,18,19}$ They also reported increased confidence on the part of patients as a result of responsive and accessible services. ${ }^{16}$ Many similarities in patient experiences may be observed despite differences in case manager characteristics. Further studies could examine patient experience of CM provided by other health care professionals such as social workers or medical assistants, ${ }_{1}^{8}$ as well as the perspectives of clinicians and nurses who provide care. Further research could also compare cost and quality of services for patients who experienced case management and those who did not.

While the global experience of most patients and family members was very positive, some participants raised issues to consider when developing future $\mathrm{CM}$ interventions for frequent users. Given the vulnerability of this clientele, the CM nurse should be able to do home visits with patients who have severe functional disabilities. Ways to reduce travel costs and multiple visits should be encouraged. It is also important to ensure that patients fully understand $\mathrm{CM}$ at recruit- ment into the intervention and that they have ample opportunity to ask questions during the process.

\section{Strengths and Limitations of the Study}

Strengths of our study include the variety of backgrounds of the authors (family medicine, nursing, social work, and anthropology), which allowed for good triangulation of perspectives when analyzing the data. Also the conceptual model and the approach used to evaluate patients' and family members' experience of care integration were patient-centered. On the other hand, although we tried to recruit participants with both positive and negative experiences of the $\mathrm{CM}$ intervention, it is possible that unsatisfied patients refused to participate in the interviews. Implementation and evaluation of $\mathrm{CM}$ were done during the same period (6 months). Despite very positive experiences, it is possible that the intervention did not reach its full potential in that time. Although we reached data saturation in our interviews with the sample of patients, we consider that perceptions of family members could be further explored. Finally, experience of any intervention designed for frequent users of health care services might depend on the health system payment and organization scheme in the country.

To read or post commentaries in response to this article, see it online at http://www.annfammed.org/content/13/6/523.

Key words: patient care management; frequent users of health care; patient experience; chronic disease; primary care; nursing

Submitted April 21, 2015; submitted, revised, August 25, 2015; accepted August 31, 2015.

Funding support: This project received financial support from the Fonds de recherche du Québec en santé.

Acknowledgments: We would like to acknowledge the patients and family members who participated in this study and Ms Susie Bernier for her editorial assistance.

Supplementary materials: Available at http://www.AnnFamMed. org/content/13/6/523/suppl/DC1/.

\section{REFERENCES}

1. Bodenheimer T, Berry-Millett R. Follow the money-controlling expenditures by improving care for patients needing costly services. N Engl J Med. 2009;361(16):1521-1523.

2. Department of Health. Caring for People With Long Term Conditions: An Education Framework for Community Matrons and Case Managers. London, England: Department of Health; 2006.

3. Commission de la réforme des services publics de l'Ontario. Des Services Publics Pour la Population Ontarienne: Cap sur la Viabilité et L'excellence. Ottawa, Canada: Gouvernement de I'Ontario; 2012.

4. Hansagi $H$, Olsson M, Sjöberg S, Tomson Y, Göransson S. Frequent use of the hospital emergency department is indicative of high use of other health care services. Ann Emerg Med. 2001;37(6):561-567. 
5. Byrne M, Murphy AW, Plunkett PK, McGee HM, Murray A, Bury $G$. Frequent attenders to an emergency department: a study of primary health care use, medical profile, and psychosocial characteristics. Ann Emerg Med. 2003;41(3):309-318.

6. Sutherland D, Hayter M. Structured review: evaluating the effectiveness of nurse case managers in improving health outcomes in three major chronic diseases. J Clin Nurs. 2009;18(21):2978-2992.

7. Sweeney L, Halpert A, Waranoff J. Patient-centered management of complex patients can reduce costs without shortening life. Am J Manag Care. 2007;13(2):84-92.

8. Freund T, Peters-Klimm F, Rochon J, et al. Primary care practicebased care management for chronically ill patients (PraCMan): study protocol for a cluster randomized controlled trial [ISRCTN56104508]. Trials. 2011;12:163.

9. Randall S, Daly G, Thunhurst C, Mills N, Guest DA, Barker A. Case management of individuals with long-term conditions by community matrons: report of qualitative findings of a mixed method evaluation. Prim Health Care Res Dev. 2014;15(1):26-37.

10. Reilly S, Abell J, Brand C, Hughes J, Berzins K, Challis D. Case management for people with long-term conditions: impact upon emergency admissions and associated length of stay. Prim Health Care Res Dev. 2011;12(3):223-236.

11. Huws DW, Cashmore D, Newcombe RG, Roberts C, Vincent J, Elwyn G. Impact of case management by advanced practice nurses in primary care on unplanned hospital admissions: a controlled intervention study. BMC Health Serv Res. 2008;8:115.

12. Lee $\mathrm{KH}$, Davenport L. Can case management interventions reduce the number of emergency department visits by frequent users? Health Care Manag (Frederick). 2006;25(2):155-159.

13. Sledge $W H$, Brown $K E$, Levine JM, et al. A randomized trial of primary intensive care to reduce hospital admissions in patients with high utilization of inpatient services. Dis Manag. 2006;9(6):328-38.

14. Latour CHM, Bosmans JE, van Tulder MW, et al. Cost-effectiveness of a nurse-led case management intervention in general medical outpatients compared with usual care: an economic evaluation alongside a randomized controlled trial. J Psychosom Res. 2007;62(3):363-370.

15. National Collaboration for Integrated Care and Support. Integrated Care and Support: Our Shared Commitment. London, England: National Collaboration for Integrated Care and Support; 2013.

16. Leighton Y, Clegg A, Bee A. Evaluation of community matron services in a large metropolitan city in England. Qual Prim Care. 2008; 16(2):83-89.

17. Taylor EF, Machta RM, Meyers DS, Genevro J, Peikes DN. Enhancing the primary care team to provide redesigned care: the roles of practice facilitators and care managers. Ann Fam Med. 2013;11(1):80-83.
18. Williams V, Smith A, Chapman L, Oliver D. Community matrons-an exploratory study of patients' views and experiences. J Adv Nurs. 2011;67(1):86-93.

19. Sargent P, Pickard S, Sheaff R, Boaden R. Patient and carer perceptions of case management for long-term conditions. Health Soc Care Community. 2007;15(6):511-519.

20. Sandelowski M. What's in a name? Qualitative description revisited. Res Nurs Health. 2010;33(1):77-84.

21. Chouinard M-C, Hudon C, Dubois M-F, et al. Case management and self-management support for frequent users with chronic disease in primary care: a pragmatic randomized controlled trial. BMC Health Serv Res. 2013;13:49.

22. Ministère de la Santé et des Services sociaux. Family medicine groups. http://www.msss.gouv.qc.ca/en/sujets/organisation/gmf.php. Accessed Dec, 2014.

23. Crabtree BF, Miller WL. Doing Qualitative Research. Thousand Oaks, CA: Sage Publications Inc; 1999.

24. Kvale S. InterViews: An Introduction to Qualitative Research Interviewing. Thousand Oaks: Sage Publications Inc; 1996.

25. Poupart J. L'entretien de type qualitatif: considérations épistémologiques, théoriques et méthodologiques. In: Poupart J, Groulx LH, Deslauriers JP, Laperrière A, Mayer R, Pires AP, eds. La recherche qualitative Enjeux épistémologiques et méthodologiques. Montréal, Canada: Gaëtan Morin; 1997:173-209.

26. De Silva D. Measuring Patient Experience. London, England: The Health Foundation; 2013.

27. Miles MB, Huberman AM. Analyse des données qualitatives. 2nd ed. Paris: De Boeck; 2003.

28. Creswell JW. Research design: Qualitative, Quantitative, and Mixed Methods Approaches. 3rd ed. Thousand Oaks, CA: Sage Publications Inc; 2009.

29. Sandelowski M. Whatever happened to qualitative description? Res Nurs Health. 2000;23(4):334-340.

30. Department of Health. Supporting People with Long Term Conditions: Liberating the talents of nurses who care for people with long term conditions. London, England: Department of Health; 2005.

31. Edmonstone J, Mackenzie H. Practice development and action learning. Pract Dev Health Care. 2005;4(1):24-32.

32. Board M, Symons M. Community matron role development through action learning. Primary Health Care. 2007;17(8):19-22. 